\title{
Precision Diagnostic Disc Injections
}

\author{
Joseph D. Fortin, DO
}

Spinal pain is an important public health problem affecting the population indiscriminately. The structures responsible for pain in the spine include the vertebrae, intervertebral discs, spinal cord, nerve roots, facet joints, ligaments, muscles, atlanto-occipital joints, atlanto-axial joints, and sacroiliac joints. Even though disc herniation, facet joints, strained muscles, and torn ligaments have been attributed to be the cause of most spinal pain, either in the neck and upper extremities, upper and mid back, or low back and lower extremities, disorders of the disc other than disc herniation have been implicated more frequently than any other disorders.

Once stifled by misinformation, discography now has applications in a number of clinical settings. While cervical and lumbar discography is well studied and well known, thoracic discography is in its nascent stages of clinical ap- plication. The value of discography lies in its ability to produce pain and thereby identify a "pain generator." This allows treatment to be based on the specific cause of pain. The three primary components of diagnostic disc injection are: provocation/analgesia, discometry, and nucleography.

Despite the recent exponential growth of noninvasive spinal technology, diagnostic disc injection remains the sole direct method for definitively determining whether a disc is a physiological pain generator. It is clear that discography is a safe and powerful complement to the overall clinical context.

Keywords: Cervical disc injection, thoracic disc injection, lumbar disc injection, nucleography, discography, discometry

\section{HISTORICAL CONSIDERATIONS}

The controversy surrounding discography provides an appreciation of its shaky beginnings. Once stifled by misinformation, discography now has applications in a number of clinical settings. The first to create widespread interest in the disc as a source of pain were Mixter and Barr with their 1934 hallmark description of the herniated nucleus pulposus (1). This mechanical model detailed a lumbar posterolateral prolapse with direct nerveroot compression and secondary radiculopathy. The work Mixter and Barr (1) generated became the central model of spine pain, which preoccupied the medical community and diverted attention from other possible causes. Medical schools continue to propagate the neurocompressive model as the primary cause of spine pain; yet, in actuality, it accounts for a relatively small percentage of all patients presenting with axial complaint(s) (2-4).

From Spine Technology and Rehabilitation, Fort Wayne, Indiana. Dr. Fortin is medical director at Spine Technology and Rehabilitation and clinical assistant professor of rehabilitation medicine at Indiana University School of Medicine. Address correspondence: Joseph Fortin, DO, Spine Technology and Rehabilitation, PC, 7230 Engle Road, Suite 210, Fort Wayne, IN 46804
In 1948, Hirsch (5) injected procaine into a herniated disc and reported relief of sciatica. This caused scientists to query the existence of an intradiscal pain mechanism. Roofe's (6) 1940 revelation of anulus fibrosis innervation provided an incentive for conceptualizing the disc as a pain source independent of a neurocompressive paradigm. Nearly half a century passed before there was clinical validation of Roofe's (6) discovery. Vanharanta and colleagues (7) demonstrated that only anular fissures extending from the mid to outer anular regions significantly correlated with pain upon provocation injection.

The clinical relevance of anular intervention may seem diaphanous by modern standards; in Roofe's (6) time it was enigmatic. With the combined information available today, which includes the awareness of potent inflammatory mediators within the nucleus of disrupted discs (8) and low-pressure (chemical) activation of anular nociceptors, (9) the need to expand the concept of spine pain beyond a pure mechanical model becomes obvious. Parenthetically, the rich innervation of the mid to outer layers of the anulus has since been substantiated by four independent investigations using sophisticated staining 
and magnification techniques (10-13).

In 1944, four years after Roofe's (6) discovery, Lindblom (14) demonstrated the presence of radial anular fissures upon injected cadaveric discs. This historically significant observation was manifested as he watched the red dye leaking from the injected nucleus into attenuated anular areas. Could disc injections be employed to detect anular pathology in patients with low back pain? Lindblom (14) had stumbled upon a potentially powerful diagnostic tool. He was reticent to clinically apply it, however, given the warnings of Pease (15). Pease's (15) admonitions were in the form of case reports that showed disc damage associated with inadvertent disc puncture upon attempted lumbar thecal puncture in children with purulent meningitis (16). Most likely, the disc "damage" was iatrogenic discitis. It is no surprise that such claims of disc damage, secondary to disc puncture, have never been rigidly validated $(17,18)$. Conversely, Lindblom $(19,20)$ was prompted by Hirsch and coworkers $(21)$ who noted concordant pain provocation with saline discal distention and no secondary disc "damage" on intraoperative disc injections. Lindblom (19) persevered and, later that same year (1948), his case reports became a catalyst for future investigations, when he reported the nucleographic patterns of 15 discs in 13 patients.

In the late 1940 s and 1950 s, the Scandinavian reports surrounding lumbar discography provided opportunities for comparable explorations in other areas of the spine $(5,20,22)$. Working independently, in the late 1950s, Smith and Nichols (23) and Cloward (24) developed similar cervical disc-injection techniques for evaluating patients with cervicocephalgia and shoulder-girdle pain. They found that injection of symptomatic discs could reproduce patient axial complaints, thereby identifying painful discs or differentiating primary discogenic versus neurogenic pain. To this end, Smith and Robinson (25) and Cloward (26) employed discography to select the proper levels for their cervical fusion techniques (still practiced to date).

By the early 1960s, discography seemed capable of replacing myelography as the premier disc-imaging study. Several large studies had enthusiastically proclaimed the contrast roentgenography study of discs an acute diagnostic tool that could prove superior to myelography in evaluating patients with internal disc pathology $(16,27)$.

The prodiscography momentum abruptly shifted following the 1964 and 1968 investigations of Holt $(28,29)$.
Using 50 penitentiary inmates as subjects, Holt studied 148 cervical discs with sodium diatrozoate (an irritating contrast medium). Fluoroscopic guidance was not employed and the injection technique was suspect in mechanical performance, discometric data, and imaging results (30). Holt (29) reported, "Injections into any cervical disc cause(s) great pain..." Based on his investigations of asymptomatic penitentiary inmates, Holt (29) maintained that $100 \%$ of cervical disc injections were falsepositive, ie, erroneously painful. He characterized previous reports of "reproduction of discogenic pain by injection of the responsible disc space" to be "fallacious." Holt (29) sought to demonstrate that a disc which is internally disrupted, or nondemonstrable on myelography, should not be an indication for surgery. He concluded that, "The volume of injectable media is also quite unreliable as an indication of pathology, since $93 \%$ of perfectly normal discs allow rapid extravasation."

During Holt's (29) era, the disc was not considered a primary putative pain source - only secondarily capable of causing pain via neurocompression. In turn, many clinicians since have been reluctant to ascribe symptoms to a disc, however internally disrupted, which is not producing direct pressure on a nerve root. Klafta and Collis (30, 31 ) noted that pain on injection was indicative of disc abnormality, but not diagnostic of protrusion. These authors $(30,31)$ therefore discounted discography in general; as one later concluded, induced pain, even if similar to the presenting symptoms, was of no diagnostic value.

Although Holt's study (29) discouraged widespread acceptance of cervical discography, many authors since have reported favorable experience with discography in evaluating patients with chronic cervical syndromes (32-44). Several studies clearly define a viable role for diagnostic disc injections in selecting symptomatic/deranged levels for a proposed anterior cervical fusion.

The same holds true for Holt's lumbar study in which he reported that $37 \%$ of lumbar disc injections were false positive or erroneously painful (28). A recent critical review found Holt's (29) methods either obsolete by modern standards or of dubious validity (43). The areas which are subject to concern are: the selection process, ie, volunteer penitentiary inmates, and high technical failure rate, ie, the inability to successfully inject some discs. This weakness raises several questions. How many injections reported as nuclear were actually anular? With the significant percentage of inadvertent anular or peridiscal injections, how many evoked discogenic pain responses 
were procedurally induced by misadventure? The volunteers may have been provoked due to multiple misdirected attempts before the disc was actually cannulated. With modern techniques, on the other hand, procedural pain is relatively mild. Six lumbar injections with normal nucleograms were reported as painful. This finding conflicts with the current knowledge of neurophysiological discogenic pain mechanisms, e.g., nociceptors could not be activated by this mechanism, for the anulus was intact - only the mid to outer anulus is innervated (10-13). Holt's studies $(28,29)$ were also stifled by lack of sophisticated technology. In this regard, one of Holt's $(28,29)$ conciliatory statements was reflective: "Whether or not discography might be made relevant by a radical change in contrast media and techniques remains speculative." Holt $(28,29)$ used Hypaque, a known neurotoxic, as the contrast agent (45). Image intensifiers had been developed in the 1950 s only to limited application (46). Holt (28, 29) was resigned to plain-film radiography. In addition, computed tomography (CT) had not been invented; hence, there was no transverse imaging to verify nuclear injections or to substantiate morphological findings.

Curiously, the same year as Holt's (28) lumbar study, Wiley and colleagues (47) found (via 2,517 disc injections) a viable role for discography in the diagnostic evaluation of patients with axial pain and no definite disc prolapse on myelography. Wiley and colleagues' (47) study was overshadowed by Holt's studies $(28,29)$ and, until recent years, the medical community at large seemed impervious to discography reports.

Employing modern techniques, a recent well-controlled prospective study of Walsh and coworkers (48) disproved Holt's (28) lumbar data. Unlike the Holt study (28), the study of Walsh and coworkers (48) considered a provocative discogram positive only if the disc was roentgenographically abnormal and the patient's pain pattern was reproduced during the administration of the injection. Walsh and coworkers (48) found discography to be a highly specific and reliable method of distinguishing symptomatic versus asymptomatic discs. The false-positive rate in the study by Walsh and coworkers (48) was $0 \%$, as compared to $37 \%$ in Holt's (28) study.

From the 1940s through the 1960s, discography found a place in the wake of myelography - only to be dismissed because of misinformation. Still, Holt $(28,29)$ deserves recognition. His desire to prevent unnecessary or "kneejerk" surgery was clear through his pointed commentary. He warned against "overdiagnosis" and basing surgery on technologies which had not been confirmed by controlled studies. In effect, how does one definitely evaluate patients who have radicular-like symptoms or primary axial pain without an obvious neurocompressive discogenic lesion? Many new investigations have disclosed important applications for both cervical and lumbar diagnostic disc injections in fusion planning (43, 44, 47, 49-51). Specifically, if the levels selected for fusion are based on discography, the success rate is high.

In contrast to cervical and lumbar discography, thoracic discography is in its nascent stages of clinical application. Simmons and Segil (43) may have provided the first description of dorsal disc injections in 1975. They discussed a 42-year-old man suffering from midthoracic pain, radiating on both sides in a band-like fashion with associated T5 hypesthesia. An explanation of their injection technique is accompanied by a radiographic nucleographic figure suggesting a posterior anular fissure at T5/6. Simmons and Segil (43) noted that the patient experienced reproduction of his symptoms upon injection. Likewise, Schellhas and Pollei (52) performed 250 thoracic discograms without complication - thus finding thoracic discography safe and effective in evaluating dorsal pain and disc degeneration.

The value of discography lies in its ability to reproduce pain and thereby identify a "pain generator." This allows treatment to be based on the specific cause of pain. Most often provocative discography is used as a guide in considering surgical and/or nonsurgical treatment options.

\section{CANDIDACY FOR DISCOGRAPHY}

According to the position statement on discography by the Executive Committee of the North American Spine Society (53),

Discography is indicated in the evaluation of patients with unremitting spinal pain, with or without extremity pain, of greater than 4 months' duration, when the pain has been unresponsive to all appropriate methods of conservative therapy. Before discography, the patients should have undergone investigation with other modalities which have failed to explain the source of pain; such modalities should include, but not be limited to, either CT scanning, (MRI) scanning and/or myelography. In these 


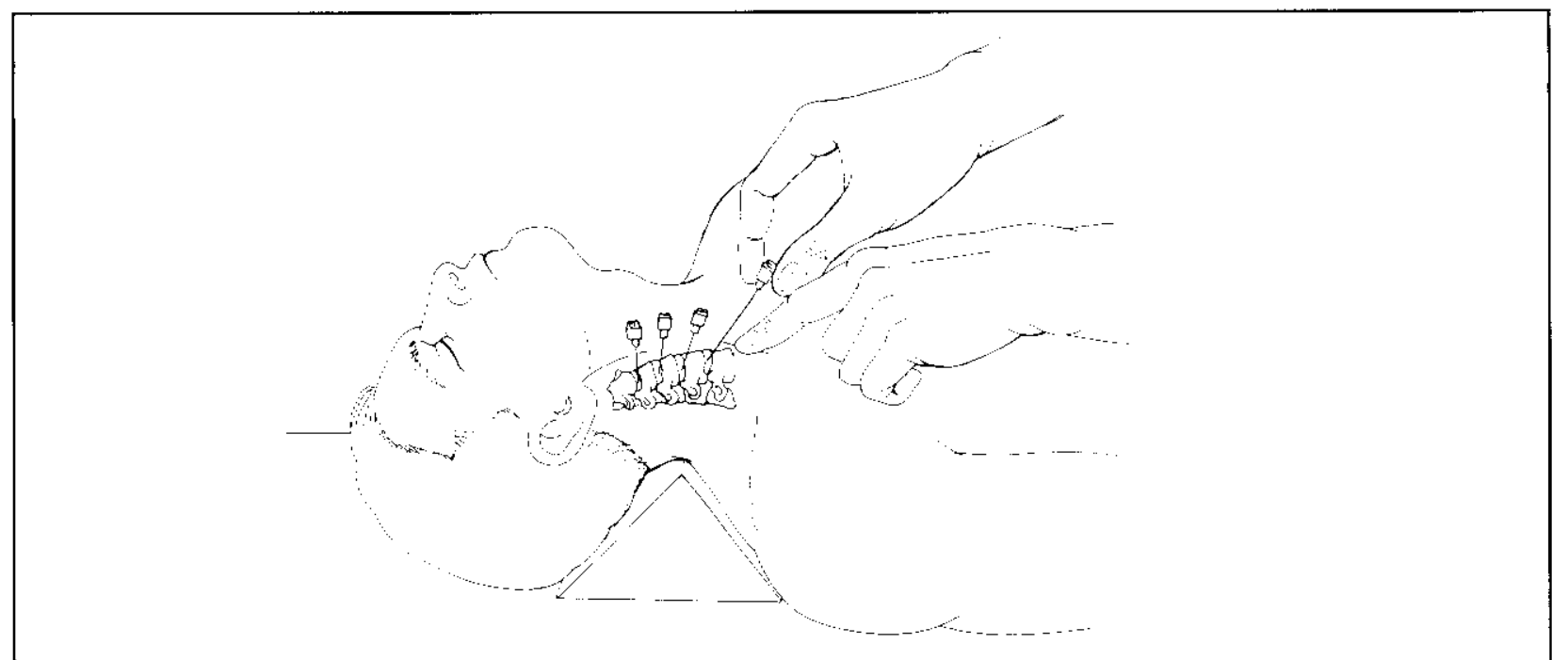

Fig. 1a. While in a supine position. the head and neck are extended over a triangular pillow. The index finger applies firm pressure to displace airway and vessels from the right anterior oblique needle pathway.

circumstances, discography, especially when followed by CT scanning, may be the only study capable of providing a diagnosis or permitting a precise description of the internal anatomy of a disc and a detailed determination of the integrity of the disc substructures. $\Lambda \mathrm{d}$ ditionally, the anatomic observations may be complicated by the critical physiological induction of pain. which is recognized by the patient as similar to or identical with his/her complaint. By including multiple levels in the study, the patient acts as his/her own control for evaluation of the reliability of the pain response.

Other indications for discography include: (1) ruling out secondary internal disc disruption or recurrent herniation in the postoperative patient; (2) exploring pseudoarthrosis: (3) determining the number of levels to include in a spine fusion; and (4) identifying the primary symptom-producing level when chemonucleolysis (enzymatic hydrolysis) or anular denervation (via thermocoagulation with an intradiscal catheter or a radiofrequency probe) is contemplated $(4,54-57)$.

It remains clear that discography is reserved as a presurgical or prethermocoagulation diagnostic tool in most situations. Predicating treatment on a rapidly established diagnosis is the key to successful patient care and to prevention of long-term patient disability from misdiagnosis/improper treatment and recidivism. If a patient has failed an initial trial of aggressive functional restoration, the employment of spinal diagnostic injections (including discography) can be extremely effective in pinpointing the pain generators. Obviously, the potential for complications should be considered in the decision process before the patient undergoes any spinal injection procedure.

\section{CERVICAL DIAGNOSTIC DISC INJECTIONS}

Following sedation the patient is sterilely prepped and draped in the supine position (Fig la). Under the lateral beam of a C-arm, the segmentation count remains the first order of the procedure. A rule of thumb is to count down from the C2-3 level to at least one disc space below the lowest segment intended for study, Longitudinal, downward traction on the bilateral upper extremities is often necessary to visualize the lower cervical segments, as the overlying shoulders cause beam attention. This "screening process" allows an estimation of the orientation of each disc space, for the needle must enter at an angle corresponding with the amount of lordosis at the selected level

The anterro-posterior beam from an overhead fluoroscopy tower is then used to visualize the appropriate interspace. The right uncinate process is then identiticd as a landmark (Fig 1b). The left index finger applies firm pressure to divide the great vessels laterally and the laryngeal

Pain Physician Vol. 3, No. 3, 2000 


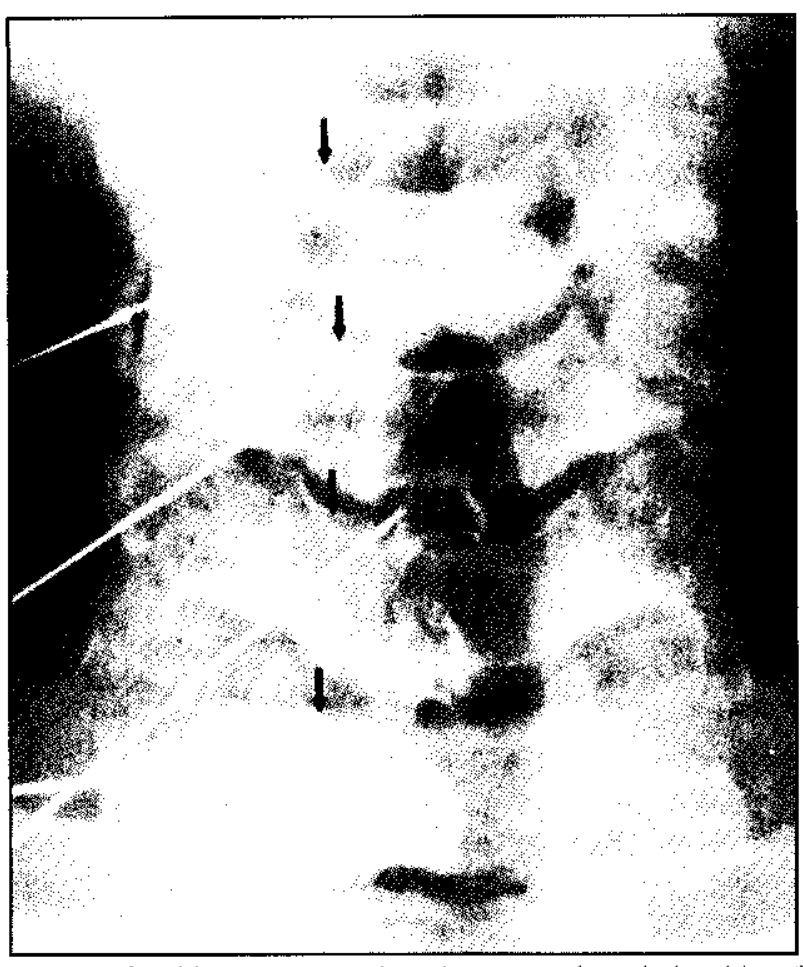

Fig. 1b. On this posteroanterior view. note the relationship of the 25-9. 31/2" spinal needles to the uncinate processes (arrowst. as well as the central nuclear regions.

structures and trachea medially. This mancuver exposes a safe and adequate path for the right anterolateral needle trajectory, providing accessibility to the dise while avoiding the great vessels, larynx, thyroid, and esophagus. The medial border of the sternocleidomastoid muscle serves as a relative skin-surface marker for the needle position at each respective level. At the $\mathrm{C} 2-3$ and $\mathrm{C} 3-4$ levels the hypopharynx must be avoided with a lateral entry point. A 25-gauge, 3.5-inch spinal needle is then directed under the $\Lambda P$ beam of an image intensifier into the selected interspace. Occasionally, the tensile strength of a 22 -gauge needle is required to circumvent anterior spondylitic ridges or spurs.

The tip of the left index finger not only applies pressure at the correct site but also serves as a marker for percutaneous entry (Fig. la). If the needle is directed past the medial aspect of the right uncinate process of the subadjacent vertebrae toward the center of the interspace, it will find its way to the central nuclear zone. For depth confirmation, the novice discographer should learn to strike the endplate of the subadjacent vertebrae prior to puncturing the anulus and then slightly withdraw and direct the needle upward into the disc space. Once the skin and subcutaneous tissue are penetrated, the needle

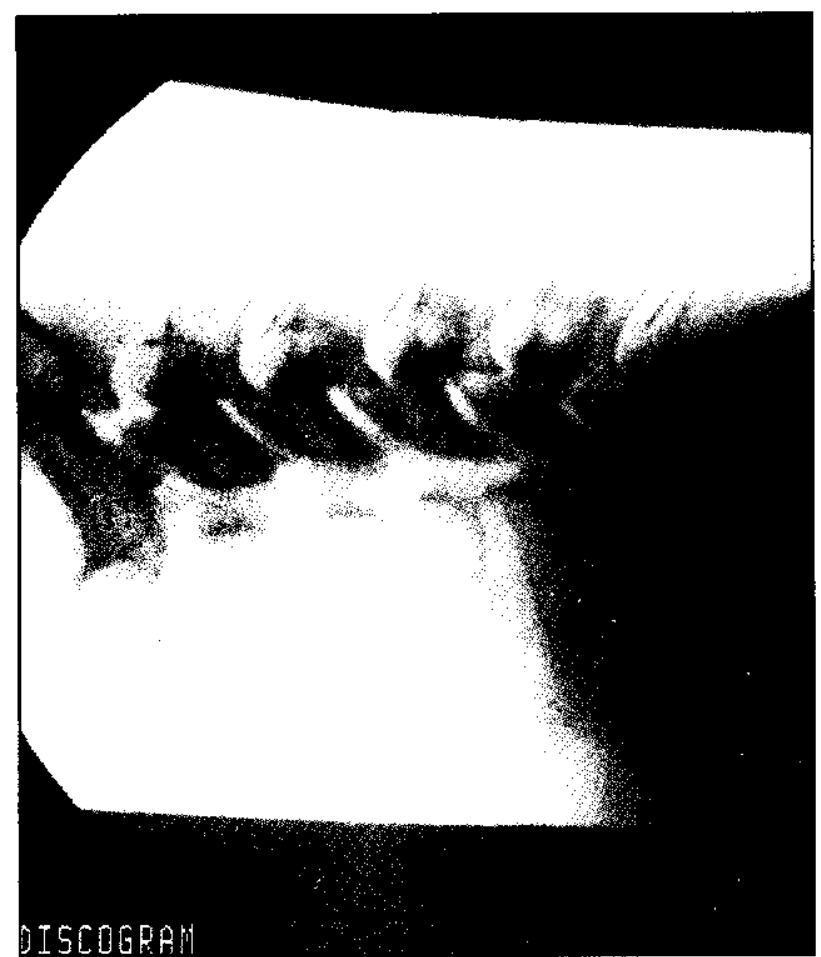

Fig. 1c. Lateral view. The needles have been advanced to the central nuclear region.

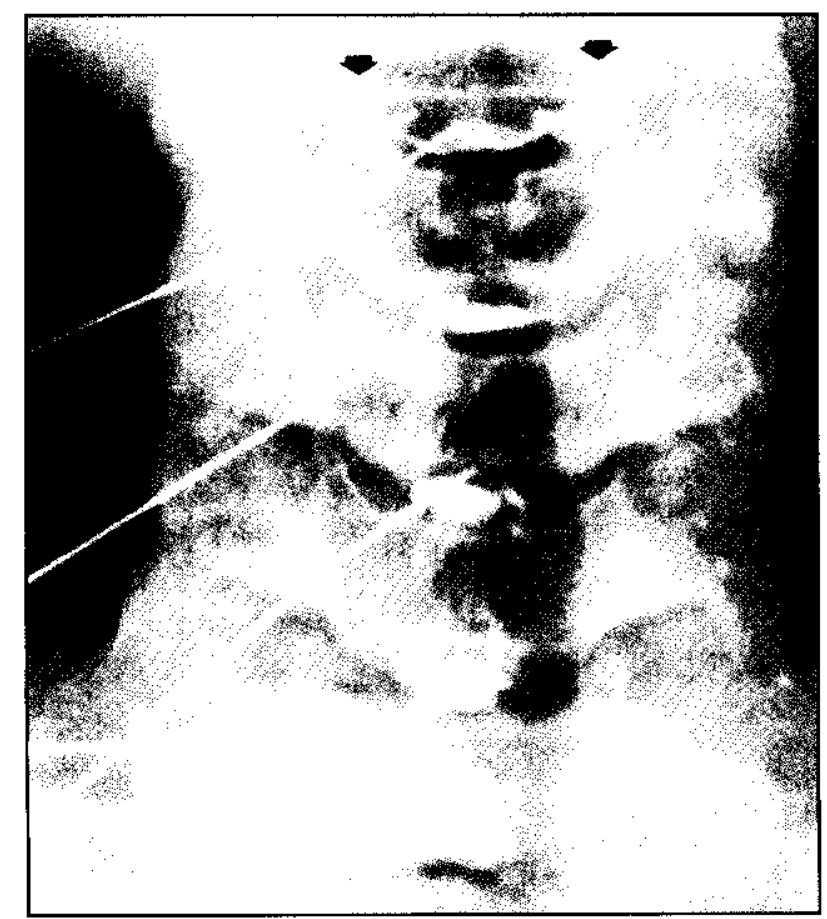

Fig. 1d. Postinjection posteroanterior projection demonstrates contrast to be well circumscribed within the nuclear zones at all levels, except for $\mathrm{C} 3 / 4$ (where contrast extends into the uncinate recesses, arrowheads). 


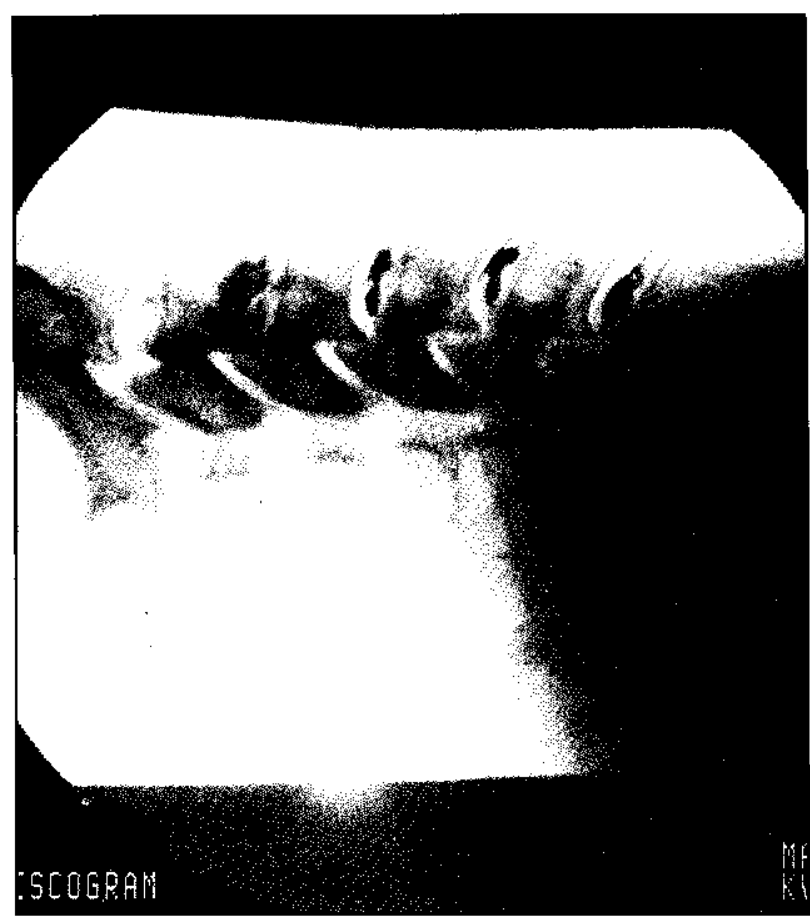

Fig. 1e. The C $3 / 4$ uncinate recess accumulation of contrasts results in "blushing" of the C 3 inlerior endplate on this lateral spot tilm.

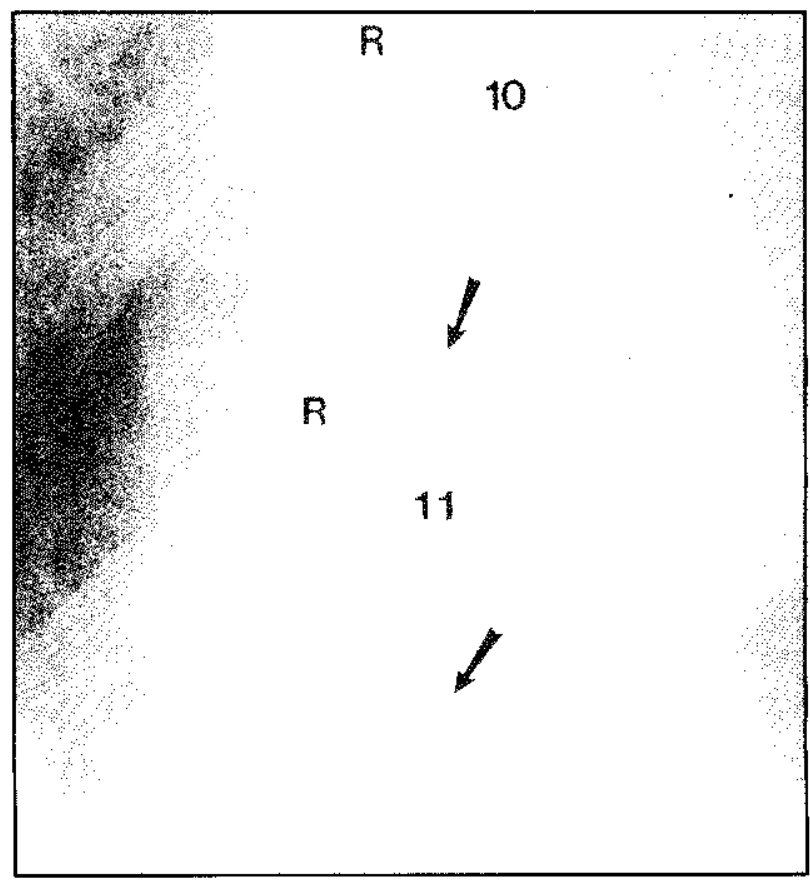

Fig. 2a. Right anterior oblique vicw demonstrates position of $25-\mathrm{g}, 3 \frac{1}{2}$ " spinal needles in relation to rib heads $(R)$ and tip of superior articular processes (arrows) (10): pedicle of $\mathrm{T} / 10$ : pedicle of Til1). will course through the platysma muscle, the areolar tissuc (between the carotid sheath and larynx), the thin straplike longus coli muscle and prevertebral fascia (Fig. 1c) before penetrating the ligamentous substance of the anterior anulus (Figs $1 \mathrm{~d}$ and $1 \mathrm{e}$ ). When the annulus is pierced, the patient will experience an abrupt, unsustained neck pain and/or shoulder girdle pain.

Relative to its lumbar counterpart, the cervical anulus is meager and the depth of the disc space narrow. One must proceed with caution when advancing the needle beyond the anulus. The needle depth and height within the disc space are now examined under the lateral bean (Figs 10 and $1 \mathrm{e})$ and adjusted accordingly.

\section{THORACIC DIAGNOSTIC DISC INJECTIONS}

Thoracic and thoracolumbar discs can be cannulated with a single 3.5-inch spinal needle or a bent-needle approach but require the utmost precision; puncture of the pleura, theca, cord or conus medullaris are potential hazards. Beam hardening from overlying structures, e.g., ribs, and a narrower interspace provide added challenges to thoracic discography.

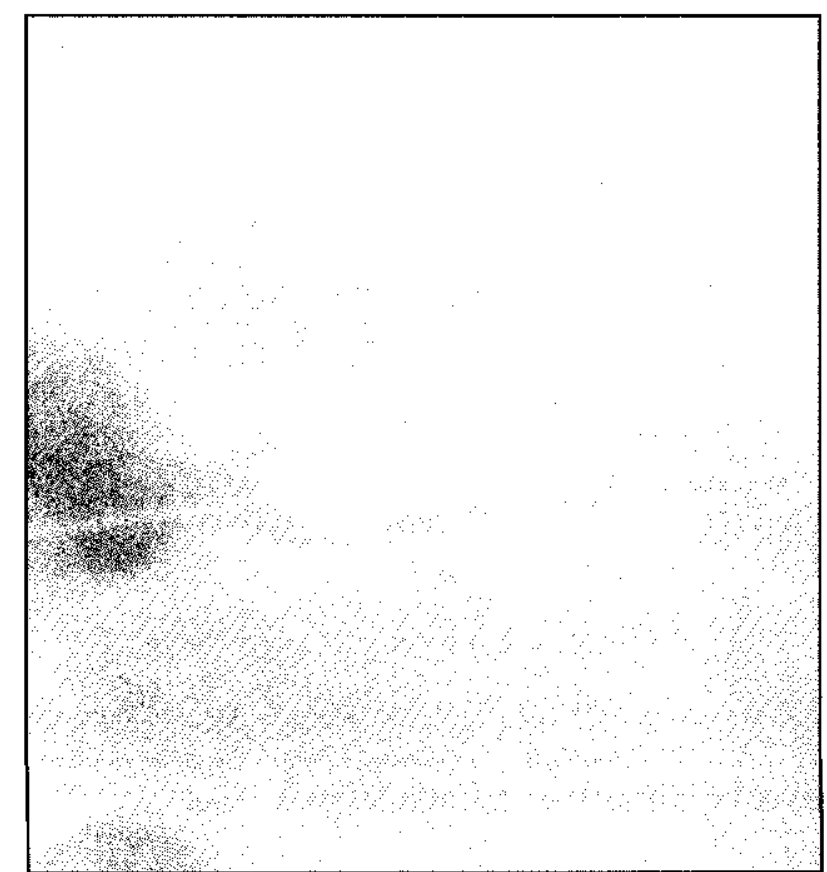

Fig. 2b. The typical oblong or elliptical nuclear contiguration of the thoracoulmbar nucleograms is shown on this lateral view. 
Thoracic disc injections may be approached similarly to lumbar discography (see the following section, "Lumbar Diagnostic Disc Injections") with a few key anatomical accommodations (58). If the patient is positioned so that the superior articular process falls just short of bisecting the interspace and the needle is directed posterior to the head of the rib (lig. 2a), the pleura will not be penetrated. An axial MRI or CT section of the thorax at the appropriate level(s) can be used as a screening modality to document specific anatomical relationships (58). Ilowever, if the pleura appears in jeopardy from a direct approach, a bent-needle technique is suggested. similar to the L5-S1 technique (58). The guide should be adjusted to the kyphotic angulation of the disc space, and a gentler bend prevents the needle from coursing into the central canal (Fig. 2b).

\section{LUMBAR DIAGNOSTIC DISC INJECTIONS}

Most Jumbar discs are readily and safely cannulated by a posterior-oblique extrapedicular approach $(44,58)$. This approach, originally described by Trosier (59), prevents the potential complications associated with thecal puncture from a transdural approach.

Lateral approaches $(60,61)$ render the segmental nerves more vulnerable -.. as evidenced upon studying the nerve pathway $(62,63)$ in relation to the proposed needle trajectories for this technique. Bowel perforation is another complication associated with the lateral approach (64). The study of high-resolution, thin-section CT and/or midto high-field-strength MRI prior to the procedure may assist in technical performances accommodating the patient's anatomy.

In general, contraindications to an extrapedicular approach include bilateral, severe lateral stenosis; bilateral, conjoint nerve-root sleeve anomalies; cystic nerve-root dilatation; and obstructing posterolateral fusion mass and or instrumentation (58).

The first step in performing a lumbar diagnostic disc injection is to select the level(s) and side of entry. If an anterior lumbar fusion is proposed for a patient with an L4-5 disc prolapse, the L3-4 and L5-SI levels must also be studied to exclude the possibility of a symptomatic fissure at an adjacent level. Failure to appreciate this potential scenario may prevent a successful surgical outcome (if all affected levels are not included in the same fusion mass).
The side of the patient from which to approach the disc(s) in question must be selected prior to the procedure. $A$ left posterior-oblique approach is used for a right posterolateral prolapse (and vice versa) to allow maximum visualization of the lesion following nucleography. The side contralateral to the patient's symptoms is also preferred in order to prevent needle-induced nociception from conllicting with the provocative response. Once the patient is adequately sedated, prepped, and draped, a segmentation count is undertaken in the prone position. Anomalous lumbosacral junctions or hemivertebrae must be identilied and numbered accordingly, for these anomalies may lead to surgery at the wrong level.

C-arm flouroscopy does not involve complex patient positioning maneuvers and allows adjustments for lordotic curve. The patient usually lies prone with the face turned to either side. When the disc is accessed by a left postero-

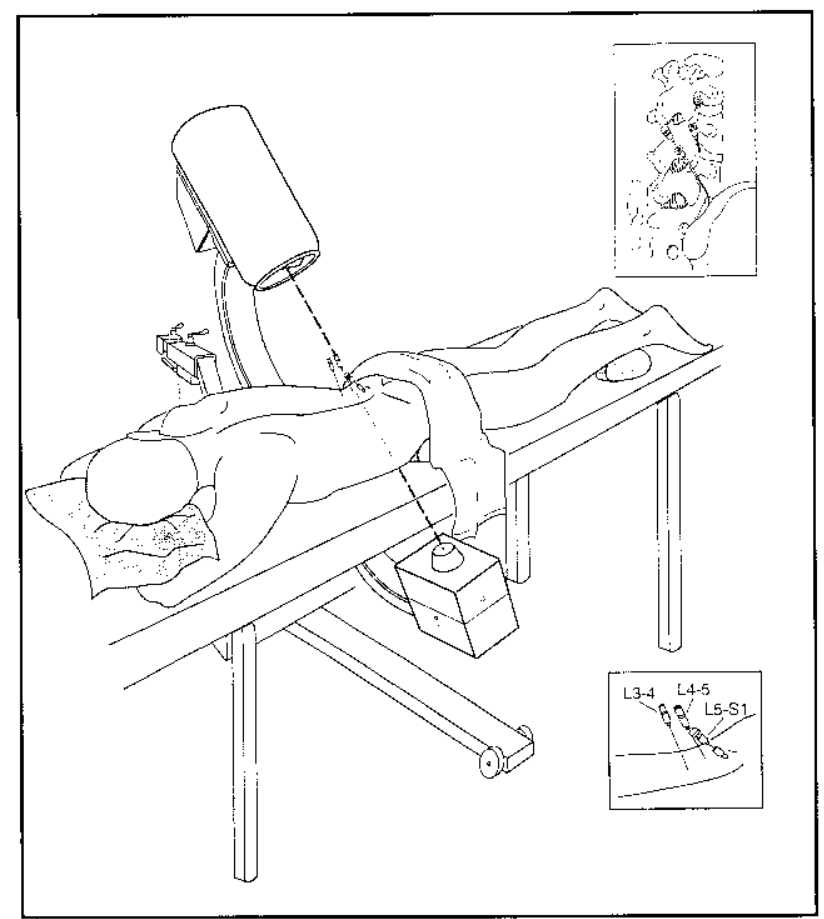

Fig. 3a. Prone position lor lumbar diagnostic disc injection using the C-arm flouroscope. The patient lies prone with the head turned to one side; a small foam wedge is positioned under the abdomen to decrease the lumbar lordosis. The $\mathrm{C}$-arm is rotated in an axial plane and is tilted cephalocaudad commensurate with the inclination of the spinal needle. Insets reveal the relationship of the needles to bony landmarks and to each other (top) and the change in inclination of the needles to the skin surface from L3-L4 to L5-S1 (bottom). Note the L5-S1 needle is inferior and modial to the L4-L5 needle. 
oblique approach, a foam wedge is placed under the left side of the patient to optimize visualization of the disc. This maneuver is necessary because the $\mathrm{C}$-arm will not rotate past 45 degrees to the left of the patient in the axial plane. Depending on the patient's lordotic curve, the clinician selects the needle trajectory angles congruent with the lordosis at each level (Fig. 3a). The operator's attention is then directed to the subjacent superior articular process of the dise to be studied. Slowly, the C-arm flouroscope is rotated in an axial plane, from a direct anteroposterior position into an oblique position, until the superior articular process of the subjacent vertebra bisects the disc space under study. Tilting the C-arm flouroscope in a cephalocaudad direction will superimpose the lateral margins of the end plates and open up the disc space for needlc entry. Sometimes the patient may need to be gently rotated into a slight prone oblique position to discern the optimum angle for approach.

When performing the procedure with an overhead tower (stationary flouroscopy unit), the lateral view is first obtained using a vertical beam, with the patient in a lateral decubitus position. This view provides a "preview" of the patient's lordotic curve to aid the clinician in selecting a needle-trajectory angle congruent with the lordosis at each level. The operator's attention is then directed to the subadjacent superior articular process of the dise being studied. Slowly, the patient is rolled forward, from a lateral decubitus position to a modified Sim's or proneoblique one. The patient's position is optimal when the superior articular process, subadjacent to the disc space under study, bisects that disc space. The patient's arm closest to the table should be outstretched overhead and a pillow fashioned between the outstretched arm and the patient's head. The lower extremities are oriented in a near "figure-of-four."

With a 25-gauge, 3.5 -inch spinal needle, a track of local anesthetic ( $1 \%$ lidocaine) is dispersed down to the superior articular process. If 25 -gauge needles are to be employed for the disc injection, local anesthesia is not necessary, as the "sting" associaled with local anesthesia is often more painful than the needle-induced nociception.

Lumbar discography can often be accomplished with 25 gauge needles; however, the needle should be selected according to the patient's body habitus. For muscular or tense patients, a 25-gauge needle may not provide enough tensile strength or "steering." A 22-gauge needle will allow ample maneuverability. Five to six inches are adequate in length for most patients, although the author

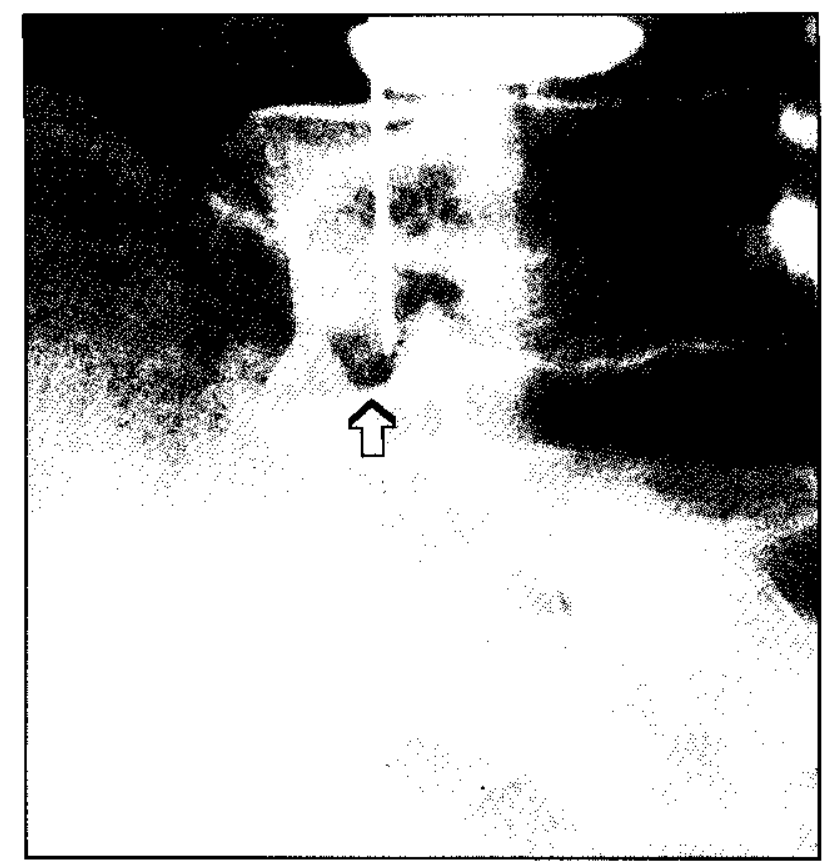

Fig. 3b. The bevel of a $20 \mathrm{~g} 31 / 2$ " trochar abuts the lateral margin of the $\mathrm{SI}$ superior articular process. The notch formed between the articular process and sacral ala is a landmark to initially advance the trochar toward (arrow) (right antcrior obliquo projection).

has been resigned to 10 -inch needles for a few obese patients. Generally, lumbar discs in thin patients are accessible with a 3.5-inch, 25-gauge needle.

The spinal needle (under an intermittent vertical fluoroscopy beam) is directed through skin, subcutaneous adipose, lumbodorsal fascia and muscle, along the lateral aspect of the tip of the superior articular process, through the anulus and into the nuclear region. At the lumbosacral junction the sensitive iliotransverse ligament must also be penetrated. Before the needle enters the "spongy" nucleus, it passes through the distinctive "springy," yet coarse, anular ligament. Upon the anulus being pierced, the patient will experience an abrupt, unsustaining pang of back pain. If the needle deflects off the superior articular process laterally, simply directing the needle tip inward (toward the disc) and the bevel outward will reorient it toward the nucleus.

As noted above, the tip of the superior articular process is a general reference point, but needle position can be adjusted according to the height of the superior articular process in relation to the segmental nerve root and endplates. The tip of the long and narrow superior articular process may lie dangerously close to the dorsal- 


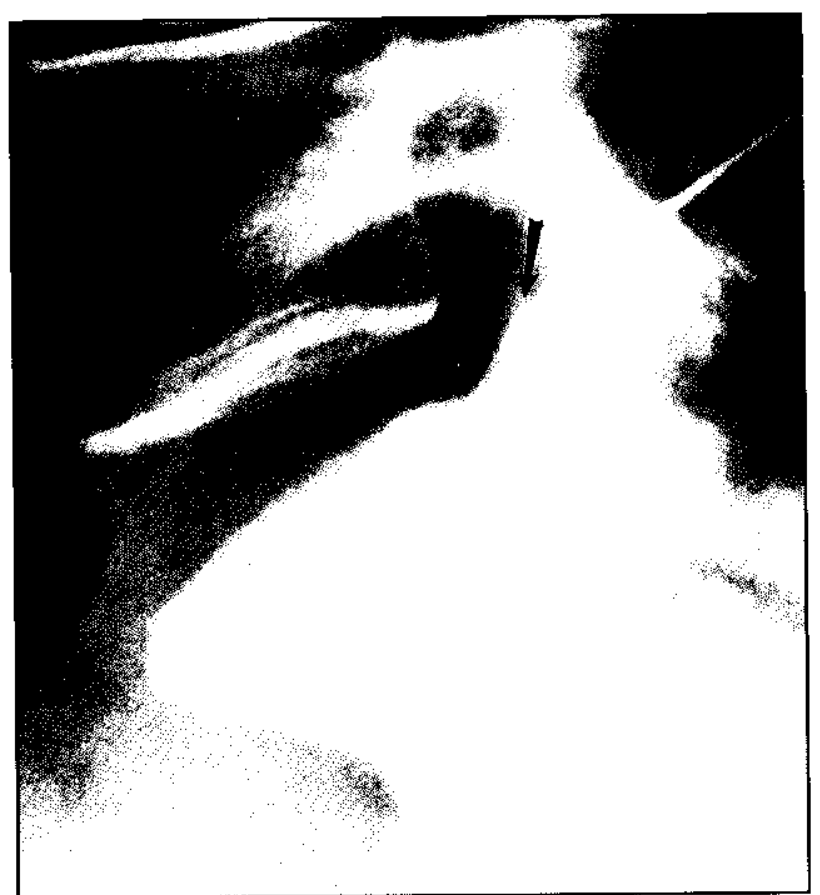

Fig. 3c. Lateral view allows the trochar to be advanced (within the inferior aspect of the 1.5 root canal) to the anterior margin of the $\mathrm{S} 1$ superior articular process (arrow).

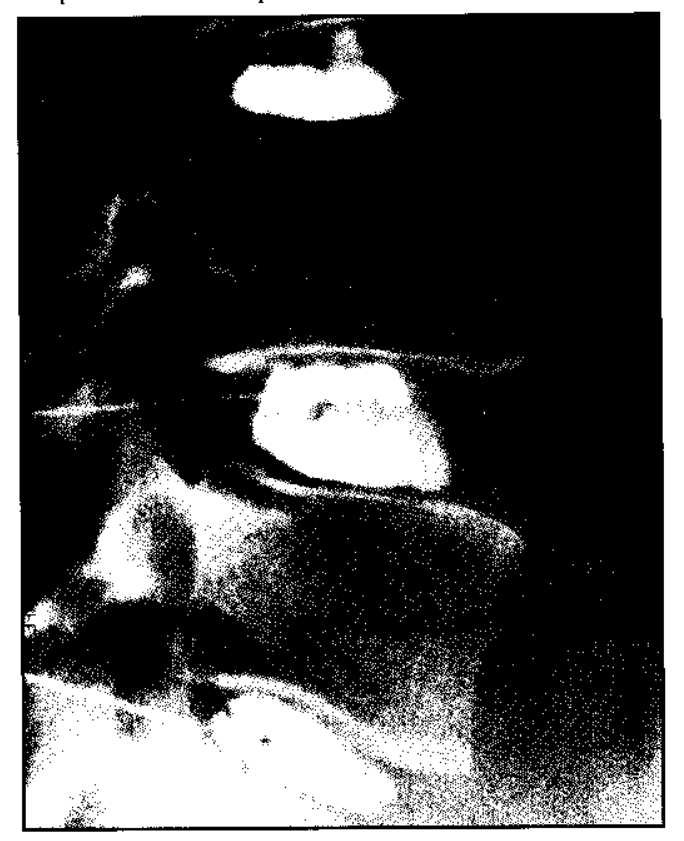

Fig. 3d. Lateral projection of the lumbar spine discloses normal nucleograms at the lower three mobile segments. The bilobulated appearance of the L3/4 and L $4 / 5$ dises is secondary to the normal maturational development of intranuclear clefts. Smooth outer margins and spherical configurations attest to the integrity of these dises. The needles are properly positioned in the mid to lower portions of the root canals. root ganglion or anterior ramus of the segmental nerve.

The litmus test of any discographer's skill can be measured against an L5-S1 disc injection. The lumbosacral inclination and iliac crest provide a challenge unique to this level. Except in patients with a low intercristal line, the anatomy of this level necessitates a bent-needle approach. This approach has been likened to the technique of Laredo and coworkers" (65) coaxial chemonucleolysis.

Selecting a method and angle of approach for cannulating the L5-S1 disc should ultimately be a function of the "safe window" available for a given trajectory. A "window" is the potential three-dimensional pathway of tissuc which would allow a needle to pass from the skin 10 its target point in a sale and uninterrupted manner (30). The body habitus, iliac crest, lordosis. L5 segmental nerve, and 1.5 transverse process must all be lactored into the trajectory selection.

With the patient in a slightly prone oblique orientation (approximately 25 degrees). a trocar is positioned as a guide for the advancement of an inner. bent procedure needle (Fig. 3b). A 3.5-inch, 20-gauge outer/5.5-inch, 25 -gauge inner is the usual combination, except for very large or rotund patients, who may require a 6-inch, 18 gauge outer/8-inch, 22- or 25-gauge inner combination.

The bony notch between the sacral ala and superior articular process of $\mathrm{Sl}$ is the target for the guide (Fig. $3 \mathrm{~b}$ ). The percutaneous site in the sagittal and axial planes must be congruent with the lumbosacral angle; likewise, the site must be lateral enough to ensure that the trocar will direct the bent needle medial (avoiding the L5 nerve). On occasion, bony obstacles (as the iliac crest or L5 transverse process) will not allow the operator to select the optimal trajectory. Such predicaments can be assuaged by skill in maneuvering the two needle systems and selecting an appropriate bend for the inner needle. Rolling the patient from side to side under tluoroseopy may help the novice imager gain a threc-dimensional appreciation for the optimal "window," commensurate with each patient's anatomy.

Once the trocar has been advanced to the aforementioned notch, its position can be observed in the lateral projection relative to the lumbosacral angle and L5 nerve rool canal (Fig. 3c). The tip of the trocar should rest at the posterior inferior border of the lateral canal. Again, the angle of the needle should be concordant with the lumbosacral inclination. If the trocar bevel is opened medi- 
ally, toward the disc, it will allow the bent needle to pass accordingly. Two other factors work upon the bent needle and act synergistically with the trocar to impart a medial movement on the inner needle: (1) The bend, which is oriented toward the disc; and (2) the bevel, which faces laterally, facilitate the tip to move medially upon purchasing soft tissue such as the anulus.

Bending the inner needle affords the diagnostician an opportunity to customize the needle shape to the patient's body habitus, as well as to impart a personalized touch to the procedure. The first consideration is to bend the needle so the bevel faces away from the direction of the bend. One method involves the needle's bending approximately 1.5 inches from the tip around the thumbnail tangentially along the needle shaft (with the index finger under the needle). Swiftly turning the end of the needle back on its shaft can create a gentle, long bend. Once the initial bend is established, applying equal and simultaneous threepoint pressure with thumb, index, and middle finger can be used to increase the arc of the bend. The key to a good "bend" is having a smooth turn and tip in the same plane as the needle shaft. Adjusting the degree of bend should be determined according to where the trocar tip lies in relation to the central nuclear zone.

With the trocar anchored firmly in one hand, the bent needle is carefully passed through until resistance is met. The resistance indicates the bent needle has engaged the bevel of the guide. Under an overhead beam, with the patient in a prone-oblique position, the bent needle is advanced so it will "steer" around the S1 superior articular process, pass under the L5 nerve root and purchase the anulus before turning into the midnuclear zone. Retracting the guide slightly while advancing the procedure needle may ensure that the target point is safely and accurately reached.

The needle position is then assessed in the lateral projection before injecting contrast. If the injection is an anular one, the contrast-dispersion pattern should be examined in several planes so the needle can be adjusted accordingly. Slight needle advancing, retracting, and redirecting usually suffices. The angle or position of the trocar rarely needs to be altered. Occasionally, the procedure needle loses its bend (upon initial pass) and it must be withdrawn and a new bent needle inserted.

\section{THE KEY COMPONENTS}

The three primary components of diagnostic disc injec- tion are: provocation/analgesia, discometry, and nucleography. Each yields data recorded separately yet viewed collectively. For example, an isolated, nonpainful, radial anular fissure may only be as significant as another incidental imaging finding. Conversely, if the same fissure is associated with an unequivocal pain response, it needs aggressive treatment that will prevent further pain and disability. The provocation aspect is not always the pivotal factor, however. A nonpainful yet dynamically incompetent disc, eg, discometry produces poor endpoint resistance and the anulus on nucleography is grossly marred by fissuring, adjacent to a proposed fusion level needs to be factored into the surgical decision algorithm - if stability is the ultimate goal.

\section{Provocation/Analgesia Assessment}

The striking structural information garnered by high-resolution, multiplanar CT and high-field-strength MRI has an attraction likened to trompe l'oeil artistic works. Yet this "eye-catching" anatomical information does not obviate the need for physiological and functional correlation. Accordingly, the marked incidence of false-positive imaging data (albeit myelography, CT, or MRI), warrants a need for provocation assessment to ratify whether a structural finding is indeed a physiological pain source (6668). Discography is the sole direct method that distinguishes symptomatic versus asymptomatic discs; hence, provocation/analgesia is the sine qua non of diagnostic disc injection.

\section{Provocation $(P)$ is recorded as follows:}

- $\quad \mathrm{PO}$ - No pain response noted upon injection/ distention of the disc with contrast or saline;

- $\quad$ P+/- - An equivocal response; vague, uncharacteristic, or discordant pain (both by nature and location);

- $\quad \mathrm{P}+$ - Definite, convincing pain provocation which is familiar to the patient yet only produces part of the symptom complex; or

- $\quad$ P++ - Exact pain reproduction and concordant with the symptom complex.

Analgesic data are codified similar to provocation (denoted $R$ for response).

- $\quad$ RO - No response to the instillation of anesthetic following a provocation elicitation;

- $\quad \mathrm{R}+/-$ - A vague, uncertain response; an improvement of " 2 " or less on a visual scale of " 0 " "10," ie, " $0 "=$ no pain; " $10 "=$ suicidal level of pain); 
- $\mathrm{R}+-$ Symptomatic relief greater than " 2 " on a 10-point VAS; or - $\mathrm{R}++-$ Complete ablation of symptoms.

Analgesic responses should be interpreted relative to the duration of anesthesia employed. If $1 \%$ lidocaine is used for subcutaneous anesthetization, grading is withheld for $1-1 / 2$ to 2 hours to allow for any residual effect to be eliminated. The longer-acting intradiscal agent should continue to act for its usual duration.

Occasionally, a patient will have a convincing provocation response, a definite provocation negative control, and little or no relief with anesthesia. This dilemma occurs most commonly in patients who have a chronic condition and significant psychosocial overlay. The author(s) noted that patients with a high-intensity zone on MRI and those who have an extremely intense provocation response often complain of heightened symptoms following the procedure (69). These patients likely have a true physiological pain generator that may be influenced by poorly understood, remote factors. The role of central neurogenic pain in these settings is uncertain. All findings should be considered carefully and discussed openly in the final analysis.

\section{Discometry}

Discometry is an estimate of the hydrodynamic competence of a disc. This information is obtained by monitoring resistance at the syringe stopped upon fluid distention of a disc and measuring the volume injected. Although exact measurements in pascals can be obtained by employing pressure manometry $(9,48,70-74)$, the amount of anular resistance monitored in a static situation is by no means an accurate reflection of anular performance in daily activities. An intact anulus does, however, have a firm, characteristically resilient endpoint; and any experienced discographer is able to distinguish a competent versus grossly incompetent anulus. If the needle tip is inadvertently in the anulus and not in the central nuclear zone, the diagnostician will find a rigid "endfield" without the unmistakable "bounce-back" resilience of a nuclear injection. On the other hand, if the anulus is disrupted, a diminished resistance at the needle hub will be appreciated.

Normal lumbar discs accept less than $3.0 \mathrm{cc}$ (7, 74-76). Volumetric data should be compared level to level as well as against the norm. On occasion, one encounters an individual with "megadiscs," e.g., normal lumbar discs accepting $4.0 \mathrm{cc}$ or greater of contrast. There is a paucity of dorsal discometric data. Most thoracic discs accept between 1 to $2 \mathrm{cc}$ of contrast, with cervicothoracic discs containing slightly less and lumbar ones, possibly more (58). Firm endpoints are obtained when injecting normal dorsal discs to capacity. Recording discometric data during operative intervention, Kambin and colleagues (77) observed that normal cervical discs accepted 0.2 to 0.4 $\mathrm{mL}$ of solution while sustaining high intradiscal pressure. In contrast, discs which allowed "posterior escape" of contrast mediums accepted greater than $1.5 \mathrm{~mL}$ at low, wavering pressures. Herniated or degenerated discs with an intact outer anular capsule held intermediate volumes ( 0.5 to $1.5 \mathrm{~mL})$ at sustained, yet intermediate pressures. In a cadaveric investigation, Saturnus and Bornscheuer (78) discovered that cervical discs which accepted in excess of $0.5 \mathrm{~mL}$ most often demonstrated posterolateral extravasation from the uncinate portions of the anulus. These studies indicate that cervical discography yields reproducible information concerning discal hydrodynamic competence. Upon injection, the intact cervical disc holds less than $0.5 \mathrm{cc}$ of solution, at which time a firm endpoint is noted.

Discographers have long considered the mechanism of pain provocation in discs with poor resilience. Questions arose, such as: "How can lumbar, thoracic, and cervical discs be provoked upon dynamic challenge?" and, "Is it likely that lumbar, thoracic, and cervical discs which are markedly disrupted and offer little or no resistance are incapable of providing a pain response upon 'distention'?" Paradoxically, Derby and colleagues (9) found that most discs are provoked at low pressures. They proposed chemical stimulation of attenuated outer anular fibers as the mechanism of pain generation.

\section{Nucleography}

Erlacher's (76) historic work was the first to demonstrate a profound correlation between radiographic and cadaveric nuclear-contrast/dye-dispersal patterns. Erlacher's (76) efforts have been embellished by Sachs and coworkers (79), who devised a grading system of nucleographic patterns using postdiscography-CT, and Vanharanta and colleagues (7), who compared each pattern with provocation data. Yu and coworkers (80) also developed a grading system of anular fissures, according to cadaveric injection study. Other authors have published their unique nucleographic scoring methods. These systems may all foster communication between physicians but do not obviate the need for accurately detailing the relationship of 
contrast to the nuclear zone, anular region, and neural elements. The presence of nociceptors within the mid to outer anulus should also be considered when interpreting postdiscography-CT nucleograms.

As the physician injects contrast medium into the disc, a direct-contrast view of the internal architecture of the disc is obtained (Figs. 1, 2 and 3). Frontal and lateral plain films are routine for cervical, thoracic, and lumbar injections.

Cervical nucleograms vary widely in configuration. They may appear spherical, discshaped, or tubular (Fig. 1). As in lumbar discograms, contrast extravasating beyond the nuclear region indicates anular disruption; however, extension of contrast from the nucleus to the uncinate recesses is common and may simply reflect disc maturation (19, 80-82). Following adolescence, linear anular clefts develop which allow communication between the nucleus and uncinate recesses $(19,82)$. Uncovertebral recesses are present only in adults. Curiously, one study demonstrated a slightly higher rate of provocation with flow of contrast to the joints of Luschka (83).

Contrast medium should be well contained in a normal disc and have smooth, round margins within the nuclear region (Fig. 3d). Lumbar nucleograms are spherical. They may appear slightly oblong or binucleated (as nuclear clefts develop with age). Any contrast extravasating beyond the central zone indicates disruption of the anulus.

Diagnostic disc injections may be followed by postdiscography CT within 1 to 3 hours. Lumbar postdiscography CT provides the diagnostician valuable information to complement findings on plain-film nucleograms $(7,79,84)$. Moreover, postdiscography CT is more sensitive than MRI for detecting anular fissure (85). Painful radial, anular fissures upon diagnostic disc injections have been disclosed in patients with normal MRI who have electrodiagnostically, irrefutable radiculopathy. Discography can also be applied to resolve conflicting findings among clinical presentation, MRI and CT.

Beyond acquiring postdiscography CT data within the necessary time frame, exercising care and precision in determining CT exam parameters is essential to complete an optimal study $(58,86)$. Five-millimeter axial sections from pedicle to pedicle with 3-to-4-mm table increments suffice for the lumbar spine. Additional selected angledgantry slices through the L5-S1 interspace may improve spatial resolution of the posterior anulus to neural structures.

Lumbar postdiscography CT has been widely applied, but technical difficulties have hampered the acceptance of cervical postdiscography CT. Owing to the small amount of contrast employed and sparse dispersal pattern, transverse imaging of the demure cervical nucleogram is challenging. High-resolution, thin-section CT (coupled with dense nonionic intranuclear contrast medium) has been used to garner novel cervical spine-imaging information.

The postdiscography data are obtained in $1.5-\mathrm{mm}$ contiguous sections employing a gantry angle commensurate with each interspace. Each disc to be studied is maximally distended with iohexol or iopamadol 300 contrast medium.

Authors initially employed postdiscography CT to resolve the dilemma of small prolapse versus pseudoprolapse, ie, extension of contrast into the recesses. If contrast medium extends to the uncinate recesses upon injecting, it may masquerade as a small prolapse on the lateral projection. Orthogonal nucleography solves this puzzle by providing an en face look at the disc space. Cervical discography CT can also be employed to visualize anular pathology, which may be confused, illdefined or absent on MRI or CT. Fissures, small protrusions, anular attenuation and nuclear degradation are, at times, indistinct on cervical MRI. Obscuration may occur, as slice thickness $(3.0$ to $5.0 \mathrm{~mm}$ ) is relatively wide compared to the cervical nuclear region. Long acquisition sequences are susceptible to motion artifact and low signal to noise. Conversely, gradient-echo images are prone to magnetic susceptibility and may erroneously create a pseudomyelographic effect. Unhampered by these problems, thin-section/high-resolution CT discography allows a more detailed view of the cervical interspace. Even the latest fast-spin echo sequences do not provide keen visualization of the internal anular matrix.

Thoracic nucleograms are intermediate in appearance. They assume features of cervical discs at the upper dorsal spine and resemble lumbar nucleograms at the thoracolumbar junction.

\section{SLEEPING BEASTS}

As the intervertebral disc has a large avascular space, the potential for bacterial growth is obvious. Discitis is the most widely recognized complication associated with di- 
agnostic disc injection, yet the incidence is reportedly low (21, 87-89), ie, $0.1 \%$ to $1.3 \%)(47,88,90-93)$. Isolation of Staphylococcal organisms suggests that skin-surface contaminates play a crucial role, although the isolation of $E$. coli and organisms indigenous to the oropharynx warn against avoiding the bowel (in lumbar injections) $(87,90,94)$ and hypopharynx and esophagus (in cervical injections) (34).

Attempting to isolate organisms in patients with discitis has proven to be elusive. It appears that in many cases the offending organism has run its natural course and neovascularization from endplate tributaries has provided rapid immunological ablation before isolation is customarily attempted $(90,91)$. Crock (95) has postulated an aseptic or chemical form of discitis. DeSeze and Levernieux (96) also alluded to a chemical discitis which leads to aseptic necrosis of the disc and secondary intervertebral arthrodesis. This destructive evolution may be attributed to the concentrated iodine product DeSeze and Levernieux (96) employed. Conversely, Fraser and colleagues' (91) experimental discitis sheep model provides compelling evidence for a sole infectious etiology. Moreover, a relatively benign and self-limited form of discitis from indolent organisms of low virulence has been suggested that may allow some organisms and the recognition of some cases to go undetected (97). These factors do not obviate the need for an appropriate index of suspicion since sequelae such as epidural and/or retropharyngeal (cervical region) abscesses can occur (92).

In patients with a dramatic increase in pain and stiffness or a change in the character of symptoms, the procedure can initially be screened with a sedimentation rate, since it is abnormal in most cases. An elevated sedimentation rate should pre-empt the application of MRI as a definitive diagnostic tool $(98,99)$. Although radionuclide scans are significantly more sensitive than plain roentgenograms $(100,101)$, MRI is now the gold standard in detection of discitis (102-104). In a comparative experimental rabbit model, MRI was found to be superior to bone scanning, with a $92 \%$ specificity, and a 95\% overall accuracy (104).

As the presenting symptoms of discitis are nonspecific, premorbid psychiatric history and/or high pain-intensity rating may obscure the clinical diagnosis. Hence, use of screening modalities in a manner which benefits these patients through cost containment and establishing or excluding the diagnosis may be challenging.

Other complications from discography include neural in- jury from direct needle trauma (either impaled segmental nerve root from a misguided thoracic or lumbar procedure or cord injury from a cervical or thoracic discography needle, pneumothorax from a misguided C7/T1 or thoracic approach), and thecal puncture headache. Postthecal puncture cephalgia or cord injury can occur when a cervical discography needle penetrates to a dangerous depth in the AP plane. It is also possible to invade the subarachnoid space at L5-S1 if the inner needle is excessively bent or the trocar malpositioned.

Smith and Kim (105) attributed an enlarging, herniated cervical disc to the performance of discography. The authors provided gradient-echo sagittal MRI images which demonstrate that the subject had a disc prolapse prior to the procedure. The prolapse was simply enlarged following the procedure. Additionally, the patient Westergren's sedimentation rate was $55 \mathrm{~mm} /$ hour (normal less than 20 ), increasing to $70 \mathrm{~mm} /$ hour, and a WBC count was 12,700 . To no surprise, a bone scan obtained within 24 hours of the procedure was normal. Two days following the procedure, the patient underwent anterior diskectomy/ corpectomy with spinal decompression (as he was experiencing progressive neurological symptoms.) The surgical findings revealed a thickened and edematous posterior longitudinal ligament, as well as scattered inflammatory cells and a few WBCs in the interspace. The clinical presentation and surgical findings are suspicious for an iatrogenically induced chemical or aseptic discitis.

Fernstrom (106) attributed six lumbar disc herniations to discography upon performing more than 1500 disc injections. He did not have the aid of fluoroscopic guidance or the ability to validate these findings with transverse imaging. Save Smith and Kim's (105) suspect report, no modern studies have related disc damage to the performance of diagnostic disc injections.

Strict adherence to a preprocedural screening protocol and precise technique in the performance of discography will ensure a low morbidity rate.

\section{DARE NOT TO VENTURE}

Cervical and thoracic discography are potentially life threatening when performed despite contraindications. For example, cervical discography in a patient with evidence of cord compression, ie, spasticity, weakness and paresthesias from a massive disc prolapse, has resulted in frank quadriplegia (107). Discography is contraindicated in patients with central stenosis, myelopathy, neoplastic, 
infectious or infiltrative processes, and relative stenosis combined with bilateral root-canal stenosis (108).

Prima facie, imaging studies which adequately assess spinal stenosis and cord compression must be examined prior to the performance of cervical discography. While MRI is superior in examining the intrinsic substance of the cord, CT affords greater osseous detail and spatial resolution in evaluating stenosis $(103,109)$. In this setting, MRI is hindered by thicker sections and variable signal intensity in degenerative osseous ridges (109). With equal or greater accuracy, intrathecal enhanced CT resolves extradural compression from bone or disc material on neural elements (theca, cord, or dural pouches) (110). Magnetic resonance imaging scanning may soon close the "gap" on all fronts with the promise of faster pulse sequences and thinner sections (obtained with 3D Fourier transformation, volume acquisition, and thinner interslice gaps).

\section{THE ZEN OF DISCOGRAPHY OR SITUATIONS THAT GIVE ONE PAUSE}

Technically challenging situations are rewarding when the skill and ingenuity of the discographer accedes to the opportunity. However, new techniques or unfamiliar regions should not be explored until the clinician acquires the necessary skill and intuitive ability, as well as a thorough understanding of the anatomy and potential for complications. Moreover, even the most basic spinal injection procedures should not be attempted without a keen grasp of orthogonal imaging (MRI and CT), pathophysiology of pain, and applied spinal biomechanics. Cadaveric dissection to investigate anatomy and the technical performance of fluoroscopically controlled procedures on cadavers form a solid foundation for accruing new skill. Magnetic resonance imaging scanning and multiplanar CT provide a segue for mentally "reconstructing" the planar fluoroscopic image into 3D. High-riding and/or far medial iliac crests combined with obesity and a steep lumbosacral inclination present a challenge to cannulate the L5/S1 disc space. Posterolateral fusion masses represent another "obstruction."

Most postposterior lumbar fusion patients necessitate a translumbar (interpedicular) approach to the lumbar disc, which punctures the theca twice and places the patient at risk for a postprocedure headache. The author developed a technique for circumventing the dura in some patients with posterolateral fusion/pedicle screw fixation. With this technique the bent inner needle courses extradurally through the central canal. Therefore, the complications (such as cephalgia) associated with thecal puncture are eliminated.

\section{DISCOGRAPHY DESPITE MRI}

Many unfortunate comparisons between MRI and discography have been perpetuated by reports that draw sweeping conclusions without an understanding of the fundamental application of the tests in question.

For example, in a 1986 study comparing MRI to discography, Gibson and colleagues (111) concluded, "MRI was shown to be more accurate than discography in the diagnosis of disc degeneration. It has several major advantages, which should make it the investigation of choice." The authors did not employ postdiscography transverse CT imaging to enhance nucleographic findings of plain films, although postdiscography CT scanning in 1986 was routine in many major spine centers $(79,84)$. If Gibson and coworkers (111) had utilized a state-of-the-art protocol, their conclusion may have been antipodal. Furthermore, the technical expertise employed in the study may be suspect, as evidenced by the statement,"...the reproduction of symptoms by discography should be one of its main advantages in helping with localization. Unfortunately, this does not seem to be a particularly reliable sign and in a patient under sedation it can be difficult to interpret." As noted above, such statements were discredited by the Walsh and colleagues study (48).

When concluding that a particular modality is the "investigation of choice," one should clearly indicate what clinical scenario(s) should pre-empt that "choice." Obviously, discography is not the study of choice as a screening tool for patients with neck or back pain. In contrast, discography is indicated for determining if an internally deranged disc in a patient with refractory axial pain (who has failed aggressive conservative care) is the pain source.

Each test should be viewed as an extension of the overall clinical context. The clinician who understands the strengths and weaknesses of each is armed with a powerful diagnostic armamentarium. A well-recognized application of this axiom is that combining CT and myelography provides additve benefits (112).

High-resolution, multiplanar CT, especially when combined with intrathecal enhancement, can provide an impressive view of the anular contour of the disc, as well as 
its spatial relationship to canals (root and central), neural elements, and posterior joints (112). Owing to superior osseous resolution, CT conveys the best view of endplates. However, CT comparatively provides little information regarding the internal integrity, biochemical constituency and state of hydration of the disc. Computerized tomography subjects the patient to ionizing radiation, and CT/ myelography is an invasive procedure with certain morbidity.

High-field strength MRI is the Stradivarius imaging modality - unsurpassed in its depiction of soft-tissue anatomy, noninvasive, and without the risk of radiation. New coil designs, 3D volume acquisitions, motion-suppression techniques, fast-spin echo and postprocessing enhancement have all added to the elegance of this modality. Some discs which appear normal on CT may clearly demonstrate various internal derangements as desiccation, fissuring and/or inflammation on MRI. Painful, inflammatory anular fissures may be enhanced with gadolinium (113) or yield focal high signal on T2-weighted images (69). The ever-expanding applications of MRI and a trend toward greater cost containment have encouraged some centers to forego conventional $\mathrm{T} 2$ spin-echo sequences. These slow-acquisition images are being "replaced" by speedier gradient-echo and fast T2 pulses. However, information regarding the signal-intensity characteristics of nuclear matrix and true spin echo may not always extrapolate to the newer pulse sequences. For instance, anular signal-intensity changes on $\mathrm{T} 2$ images which seem to correlate with pain on provocation may not share the same signal characteristics with modern sequences (70, 113).

As an imaging modality, discography, when combined with axial CT, surpasses MRI in detecting anular fissures $(80,85)$. Discography, however, is an invasive procedure and should be reserved for those patients who have unrelenting axial pain, and no definite neurocompressive lesion, who have failed aggressive functional restoration $(58,86)$.

\section{CONCLUSION}

Despite the recent experimental growth of noninvasive spinal technology, diagnostic disc injection remains the sole direct method for definitively determining whether a disc is a physiological pain generator. It is clear that discography is a safe and powerful complement to the overall clinical context. This diagnostic tool may also enhance information obtained from other imaging modali- ties or reveal new and otherwise enigmatic findings. Additionally, nucleography in the transverse mode may enhance imaging information garnered by CT or MRI.

\section{REFERENCES}

1. Mixter WJ, Barr JS. Ruptures of the intervertebral disc with involvement of the spinal canal. $N$ Eng $J$ Med 1934; 211:210.

2. Schwarzer AC, Aprill CN, Derby R et al. The relative contributions of the disc and zygapophyseal joint in chronic low back pain. Spine 1994; 19:801-806.

3. White A, Panjabi M. Clinical biomechanics of the spine. Philadelphia, JB Lippincott, 1978.

4. Sehgal N, Fortin, J. Internal disc disruption and low back pain. Pain Physician 2000; 3:143-157.

5. Hirsch C. An attempt to diagnose level of disc lesion clinically by disc puncture. Acta Orthop Scand 1948; 18:131-140.

6. Roofe PG. Innervation of the anulus fibrosus and posterior longitudinal ligament. Arch Neurol Psych 1940; 44:100-103.

7. Vanharanta H, Sach BL, Ohnmeiss DD et al. Pain provocation and disc deterioration by age. A CT/ discographic study in a low back pain population. Spine 1989; 14:420-423.

8. Saal JS, Franson RC, Dobrow R et al. High levels of inflammatory phospholipase $\mathrm{A}_{2}$ activity in lumbar disc herniations. Spine 1990; 15:674-678.

9. Derby R, Kine G, Schwarzer A et al. Relationship between intradiscal pressure and pain provocation during discography. Proceedings of North American Spine Society $8^{\text {th }}$ Annual Assembly, San Diego, 1993.

10. Bogduk N, Tynan W, Wilson AS. The nerve supply to the human lumbar intervertebral discs. J Anat 1981; 132:39-56.

11. Groen G, Baljet B, Drukker J. The nerves and nerve plexuses of the human vertebral column. Am J Anat 1990; 188:282-296.

12. Malinsky J. The ontogenetic development of nerve terminations in the intervertebral discs of man. Acta Anat 1959; 38:96-113.

13. Yoshizawa H, O'Brien JP, Thomas-Smith W. The neuropathology of intervertebral discs removed for low back pain. J Path 1980; 132:95-104.

14. Lindblom K. Protrusions of the discs and nerve compression in the lumbar region. Acta Radiol Scand 1944; 25:195-212.

15. Pease $\mathrm{CN}$. Injuries to the vertebrae and intervertebral discs following lumbar puncture. Am J Dis Child 1935; 49:849-860.

16. Collis JS Jr, Gardner WJ. Lumbar discography. An analysis of 1,000 cases. J Neurosurg 1962; 19:452461.

17. Flanagan MN, Chung B. Roentgenographic changes in 188 patients $10-20$ years after discography and 
chemonucleolysis. Spine 1986; 11:444-448.

18. Johnson RG. Does discography injure normal discs? An analysis of repeat discograms. Spine 1989; 14:424426.

19. Lindblom K. Diagnostic puncture of the intervertebral discs in sciatica. Ortho Scand 1948; 17:231-239.

20. Lindblom K. Technique and results of diagnostic disc puncture and injection (discography) in the lumbar region. Acta Irtigio /scabd 1951; 20:315-326.

21. Hirsch C, Schajowicz R, Galante J. Structural changes in the cervical spine. A study on autopsy specimens in different age groups. Acta Orthop Scand (Suppl. 109) $1967 ; 7-77$.

22. Unander-Scharin L. Diskografier. Nord Med 1957; 57:116.

23. Smith GW, Nichols P Jr. Technic for cervical discography. Radiology 1957; 68:718-720.

24. Cloward RB. Cervical diskography. Technique, indications and use in the diagnosis of ruptured cervical discs. Am J Roentg 1958; 79:563-574.

25. Smith GW, Robinson RA. The treatment of certain cervical spine disorders by anterior removal of the intervertebral disc and interbody fusion. J Bone Joint Surg (Am) 1958; 40:607-623.

26. Cloward RB. The anterior approach for removal of ruptured cervical discs. J Neurosurg 1958; 15:602617.

27. Feinberg SB. The place of discography in radiology as based on 2,320 cases. Am J Radiol 1964; 92:12751281.

28. Holt EP Jr. The question of lumbar discography. $J$ Bone Joint Surg (Am) 1968; 50:720-726.

29. Holt EP Jr. Fallacy of cervical discography. Report of 50 cases in normal subjects. JAMA 1964; 188:799801.

30. Klafta LA Jr, Collis JS Jr. An analysis of cervical discography with surgical verification. J Neurosurg 1969; 30:38-41.

31. Klafta LA Jr, Collis JS Jr. The diagnostic inaccuracy of the pain response in cervical discography. Cleveland Clin $Q$ 1969; 36:35-39.

32. Altenstein G. Erfahrungen mit der diskographic an hals und lendenwirbelsaule. Z Orthop 1967; 102:358366.

33. Bettag W, Grote W. Die bedeutung der diskographie fur die behandlung des "zervikalsyndroms." Hippokrates 1969; 40:138-141.

34. Cloward RB. Cervical discography defended (letter). JAMA 1975; 233:862.

35. Grote W, Wappenschmidt J. Uber technik und indikation zur-zervikalen diskographie. ROFO 1967; 106:721-727.

36. Hatt MU. Hohenlokalisation der cervicalen discushernie in klinik, elektromyographe (EMG) und myelographie. Disch Aeitschr Nervenheilk 1969; 197:56-65.
37. Kikuchi S, Macnab I, Moreau P. Localization of the level of symptomatic cervical disc degeneration. $J$ Bone Joint Surg (Br) 1981; 63:272-277.

38. Massare C, Bard M, Tristant H. Cervical discography. Speculation on technique and indications from our own experience. J Radiol 1974; 55:395-399.

39. Pascaud JL, Mailhes F, Pascaud E et al. The cervical intervertebral disc. Diagnostic value of cervical discography in degenerative and post-traumatic lesions. Ann Radiol (Paris) 1980; 23:455-460.

40. Roth DA. Cervical analgesic discography. A new test for the definitive diagnosis of painful-disk syndrome. JAMA 1976; 235:1713-1714.

41. Schaerer JP. Anterior cervical disc removal and fusion. Schweiz Arch Neurol Neurochirurgie Psychiatry 1968; 102:331-334.

42. $\quad$ Stuck RM. Cervical discography. Am J Roentg 1961; 86:975-982.

43. Simmons EH, Segil CM. An evaluation of discography in the localization of symptomatic levels in discogenic disease of the spine. Clin Orthop and Rel Res 1975; 108:57-69.

44. Aprill CN. Diagnostic disc injection. In Frymoyer J (ed). The Adult Spine - Principles and Practices. New York, Raven Press, 1992, pp 403-442.

45. Ruohimaa PJ, Melartin E. Neurotoxicity of iothalamates and diatrizoates, II: Historadioauptographic study of rat brains with 131-iodine-tagged contrast media. Investigative Radiol 1970; 5:22-29.

46. Curry TS, Dowdey JE, Murry RC. Christensen's Physics of Diagnostic Radiology, ed 4. Philadelphia, Lea \& Febiger, 1990; pp 165-166.

47. Wiley J, McNab I, Wortzman G. Lumbar discography and its clinical applications. Can J of Surg 1968; 11:280-289.

48. Walsh T, Weinstein J, Spratt K et al. The question of lumbar discography revisited. A controlled prospective study of normal volunteers to determine the falsepositive rate. J Bone Joint Surg (Am) 1990; 72:10811088.

49. Blumenthal S, Baker J, Dosett A et al. The role of anterior lumbar fusion for internal disc disruption. Spine 1988; 13:566-569.

50. Brodsky AE, Binder WF. Lumbar discography. Its value in diagnosis and treatment of lumbar disc lesions. Spine 1979; 4:110-120.

51. Colhoun E, McCall IW, Williams L et al. Provocation discography as a guide to planning operations on the spine. J Bone Joint Surg 1988; 70:267-271.

52. Schellhas KP, Pollei SR. Thoracic disc degeneration: Correlation of MR imaging and discography. Proceedings of North American Spine Society $8^{\text {th }}$ Annual Assembly, San Diego, 1993.

53. North American Spine Society. Position statement on discography. The Executive Committee of the North American Spine Society. Spine 1988; 13:1343. 
54. Bogduk N, Macintosh J, Marsland A. Technical limitations to the efficacy of radiofrequency neurotomy for spinal pain. Neurosurgery 1987; 20:529-534.

55. Moringlane JR, Koch R, Schafer H et al. Experimental radiofrequency (RF) coagulation with computerbawed on-line monitoring of temperature and power. Acta Neurochirugica 1989; 96:126-131.

56. Sluijter M, van Kleef M. The RF lesion of the lumbar intervertebral disc. Maastricht, Netherlands, April 1994.

57. Saal JS, Saal JA. Management of chronic discogenic low back pain with a thermal intradiscal catheter. A preliminary report. Spine 2000; 25:382-388.

58. Fortin JD. Lumbar and thoracic discography with CT and MRI correlations. In Leonard T (ed). Physiatric Procedures in Clinical Practice. Philadelphia, Hanley \& Belfus, 1995, pp 163-183.

59. Troiser O. Technique de la discographie extra-durale. J Radiol 1982; 63:571-578.

60. Day PL. Lateral approach for lumbar diskogram and chemonucleolysis. Clin Orthop 1969; 67:90-93.

61. Edholm P, Fernstrom I, Lindblom K. Extradural lumbar disc puncture. Acta Radiol Scand 1967; 6:238322.

62. Hasue M, Kunogi J, Konno S et al. Classification by position of dorsal root ganglia in the lumbosacral region. Spine 1989; 14:1261-1264.

63. Rauschning W. Normal and pathologic anatomy of the lumbar root canals. Spine 1987; 12:1008-1019.

64. Benoist M. Positioning alternatives for chemonucleolysis: Current concepts in chemonucleolysis. $J R$ Soc Med 1984; 72:47-53.

65. Laredo J, Busson J, Wybier M et al. Technique of lumbar chemonucleolysis. In Bard M, Laredo J (eds). Interventional Radiology in Bone and Joint. New York, Springer-Verlag, 1988, pp 101-122.

66. Boden S, Davis DO, Dina TS. Abnormal magnetic resonance scans of the lumbar spine in asymptomatic subjects. J Bone Joint Surg 1990; 72-A:403-408.

67. Hitselberger WE, Whitten R. Abnormal myelograms in asymptomatic patients. J Neurosurg 1968; 28:204206.

68. Wiesel SW, Tsourmas N, Feffer HL et al. A study of computer assisted tomography. I. The incidence of positive CAT scans in an asymptomatic group of patients. Spine 1984; 9:549-551.

69. Aprill CN, Bogduk N. High intensity zones in the disc anulus: A sign of painful disc on magnetic resonance imaging. Br J of Radiol 1992; 65:361-369.

70. Nachemson A, Elfstrom G. Intravital dynamic pressure measurement in lumbar discs. Scand J Rehab Med (Suppl.) 1970; 1:1-40.

71. Nachemson A. Lumbar intradiscal pressure. Acta Orthop Scand (Suppl.) 1960; 43:1-104.

72. Panjabi M, Brown M, Kindahl S et al. Intrinsic disc pressure as a measure of integrity of the lumbar spine.
Spine 1988; 13:913-917.

73. Quinnell RC, Stockdale H. Pressure standardized lumbar discography. Br J of Radiol 1980; 53:1031-1036.

74. Quinnell RC, Stockdale HR, Willis DS. Observations of pressures within normal discs in the lumbar spine. Spine 1983; 8:166-169.

75. Adams MA, Dolan P, Hutton WC. The stages of disc degeneration as revealed by discograms. J Bone Joint Surgery (Br) 1986; 68:36-41.

76. Erlacher PR. Nucleography. J Bone Joint Surg (Br) 1952; 34:204-210.

77. Kambin P, Abda S, Kurpicki F. Intradiskal pressure and volume recording: Evaluation of normal and abnormal cervical disks. Clin Orthop 1980; 146:144147.

78. Saturnus KS, Bornscheur HH. Comparative radiologic and pathologic-anatomic studies on the value of discography in the diagnosis of acute intervertebral disc injuries in the cervical spine. Rofo Fortschr Geb Rontgenstr Neuen Bildgeb Verfahr 1983; 139:651-657. 79. Sachs BL, Spivey MA, Vanharharnta H et al. A clinical grading system of CT/discography for diagnostic value in low back problems. Dallas discogram description: A new classification of CT/discography. Presented at the meeting of the North American Spine Society, Bolton Landing, NY, July 20-23, 1986.

80. Yu SW, Haughton VM, Sether LA et al. Comparison of MR and discography in detecting radial tears of the anulus: A post-mortem study. Am J Neuroradiol 1989; 10:1077-1081.

81. Payne EE, Spillane JD. The cervical spine. Brain 1957; 80:572-596.

82. Sherk H, Parke W. Developmental anatomy. In Bailey RW (ed). The Cervical Spine Philadelphia, JP Lippincott, 1983, pp 7-8.

83. Poletti SC, Handal JA. Cervical Discography: Morphology versus pain response. Boston, American Spine Society, 1992.

84. Mital MA, Thompson WC III. Role of discography enhanced by CT scanning in investigation of low back pain with sciatica. Presented at the meeting of the Federation of Spine Associations, New Orleans, LA, February 19-30, 1986.

85. Yu SW, Sether LA, Ho PS et al. Tears of the anulus fibrosis: A correlation between MR and pathologic findings in cadavers. Am J Neuroradiol 1988; 9:367337.

86. Fortin JD. Cervical discography with CT and MRI correlations. In Leonard T (ed). Physiatric Procedures in Clinical Practice. Philadelphia, Hanley \& Belfus, 1995, pp 185-195.

87. Guyer RD, Collier R, Stith WJ et al. Discitis after discography. Spine 1988; 13:1352-1354.

88. Roosen K, Bettag W, Fiebach O. Komplikationen der cervikalen diskographie. ROFO 1975; 122:520-527.

89. Volgelsang H. Discitis intervertrablis cervicalis nach 
diskographie. Neurochirurgia 1973; 16:80-83.

90. Fraser RD, Osti OL, Vernon-Roberts B. Discitis after discography. J Bone Joint Surg (Br) 1987; 69:26-35.

91. Fraser RD, Osti OL, Vernon-Roberts B. Discitis following chemonucleolysis: An experimental study. Spine 1986; 11:679-687.

92. Lownie SP, Ferguson GG. Spinal subdural empyema complicating cervical discography. Spine 1989: 14:1415-1417.

93. Milette PC, Melanson D. A reappraisal of lumbar discography. Journal De L'Association Canadienne Des Radiologists 1982; 11:176.

94. Agre K, Wilson RR, Brim M et al. Chymodiactin post-marketing surveillance: Demographic and adverse experience data in 29,075 patients. Spine 1984; 9:479-485.

95. Crock H. Practice of Spinal Surgery. New York, Springer-Verlag, 1983.

96. DeSeze S, Levernieux J. Les Accidents de la Discographie. Rev Rheum 1952; 19:1027-1033.

97. Schofferman L, Schofferman J, Zucherman J et al. Occult infections causing persistent low-back pain. Spine 1989; 14:417-419.

98. Fernand R, Lee CK. Postlaminectomy disc space infection. A review of the literature and a report of three cases. Clin Orthop 1986; 209:215-218.

99. Thibodeau AA. Closed space infection following removal of lumbar intervertebral disc. J Bone Joint Surg (Am) 1968; 50:400-410.

100. Bruschwein DA, Brown ML, McLeod RA. Gallium scintigraphy in the evaluation of disc-space infections. Concise communications. J Nucl Med 1980; 21:925927.

101. Norris S, Ehrlich MG, Keim DE et al. Early diagnosis of disc space infection using Gallium-67. J Nucl Med 1978; 19:384-386.

102. Arrington JA, Murtagh FR, Silbiger ML et al. Magnetic resonance imaging of post-discogram discitis and osteomyelitis in the lumbar spine: Case report. J Fla
Med Assoc 1986; 73:192-194.

103. Modic MT, Feiglin D, Pirano D et al. Vertebral osteomyelitis: Assessment using MR. Radiology 1985; 157:157-166.

104. Szypryt E, Hardy J, Hinton C et al. A comparison between magnetic resonance imaging and scintigraphic bone imaging in the diagnosis of disc space infection in an animal model. Spine 1988; 13:10421048.

105. Smith MD, Kim SS. A herniated cervical disc resulting from discography: An unusual complication. Spinal Disord 1990; 3, 4:392-395.

106. Fernstrom U. A discographical study of ruptured lumbar intervertebral discs. Acta Chirurgical Scand (Suppl.) 1960; 258:1-60

107. Laun A, Lorenz R, Agnoli AL. Complications of cervical discography. J Neurosurg Sci 1981; 25:17-22.

108. Verbiest H. Fallacies of the present definition, nomenclature and classification of the stenoses of the lumbar vertebral canal. Spine 1976; 1:217-225.

109. Karnaze MG, Gado MH, Sartor KJ et al. Comparison of MR and CT myelography in imaging the cervical and thoracic spine. Am J Roentgenology 1988; 150:397-403.

110. Modic MT, Masaryk TJ, Mulopulos GP et al. Cervical radiculopathy: Prospective evaluation with surface coil MR imaging, CT with metrizamide and metrizamide myelography. Radiology 1986; 161:753759 .

111. Gibson MJ, Buckley J, Mawhinney R et al. Magnetic resonance imaging and discography in the diagnosis of disc degeneration. J Bone Joint Surg (Br) 1986; 68:369-373.

112. Wilmink JT. CT morphology of intrathecal lumbosacral nerve root compression. Am J Neuroradiol 1989; 10:233-248.

113. Horton W, Daftar T. Which disc as visualized by MRI is actually a source of pain? Spine 1992; 17:164. 